Original article

\title{
Savunma Sanayinde Girişimcilik Yöneliminin Yenilikçilik Bağlamında Örgüt İklimi ile İlişkisinin İncelenmesi ${ }^{1}$ Investigation of the Relationship of in the Context of Innovation of the Entrepreneurial Orientation with Organizational Climate in the Defense Industry
}

\author{
Hüseyin Solmaz \\ Department of Management, Institute of Social Sciences, Eskişehir Osmangazi University, Eskişehir, Turkey
}

\begin{abstract}
Özet
Gelişen ve değişen çevrede organizasyonların rekabet avantajı kazanması, iç ve dış çevresine yön verebilmesi için çevresini kontrol altında tutabilmesi ve çevre koşullarına uyum sağlaması gerekmektedir. Organizasyonların bu şartları yerine getirmesi için girişimcilik yönelimi bağlamında yenilikçilik özelliğine sahip olması gerekmektedir. Organizasyonlarda girişimcilik yönelimini gerçekleştirmek için örgüt içinde olumlu bir hava yaratarak bireyin amaçlarının örgüt amaçlarıyla uyumlaştırılması ve organizasyon üyelerinin davranışlarının düzenlenmesi için uygun bir örgüt iklimine sahip olması gerekmektedir. Bu noktalardan hareketle çalışmanın temel amacı girişimcilik yönelimi bağlamında yenilikçilik ve örgüt iklimi kavramlarının ilişki düzeylerinin tespitidir

Araştırmanın evrenini Ankara ilinde faaliyet gösteren savunma sanayii çalışanları oluşturmaktadır. Araştırma kapsamına alınan katılımcı sayısı ise 448 olarak belirlenmiştir. Tez çalışmasının araştırma kısmından elde edilen veriler ile girişimcilik yönelimi bağlamında yenilikçilik ile örgüt iklimi ilişkisinde her bir değişkenin birbirleriyle ilişkisinin pozitif ve anlamlı olduğu tespit edilmiştir.

Araşsırma sonucunda elde edilen bulgular, yazın açısından önem arz etmektedir. Bu çalışma çalışanların örgütlerine yönelik girişimci yönelimi bağlamında yenilikçilik algılarının önemini ortaya koymaktadır. Bunun gerçekleşmesi için organizasyonlarda çalışanların motivasyonunu artıracak faaliyetlerin gerçekleştirilmesi gerekmektedir.
\end{abstract}

Anahtar Kelimeler: Yenilikçilik, Girişimcilik Yönelimi, Örgüt İklimi, Savunma Sanayi.

\section{Abstract}

In the developing and changing environment, organizations should able to keep their internal and external environment under control and adapt to environmental conditions in order to gain competitive advantage. In order to fulfill these requirements, organizations must innovate in the context of entrepreneurship orientation. In order to realize the entrepreneurship orientation in organizations, it is necessary to create a positive atmosphere within the organization, to harmonize the goals of the individual with the goals of the organization and to have a suitable organizational climate to regulate the behavior of the organization

\footnotetext{
* Corresponding author:

Hüseyin Solmaz, Department of Management, Institute of Social Sciences, Eskişehir Osmangazi University, Eskişehir, Turkey. Email:kkemibu@gmail.com

${ }^{1}$ Bu çalışma Eskişehir Osmangazi Üniversitesi Sosyal Bilimler Enstitüsü İşletme Ana Bilim Dalı Doktora Programında yapılan, Solmaz H, (2016) “Örgüt İkliminin Girişimcilik Yönelimi Üzerine Etkisi ve Öğrenme Yöneliminin Rolü: Savunma Sanayiinde Bir Araştırma” başlıklı tezden üretilmiştir.
} 
members. Based on these points, the main purpose of the study is to determine the relationship levels between the concepts of innovation and organizational climate in the context of entrepreneurship orientation.

The population of the research is composed of defense industry employees operating in Ankara. 448 participants included in the study. With the data obtained from the research part of the thesis, it was determined that the relationship between each variable in the relationship between innovation and organizational climate in the context of entrepreneurship orientation was positive and significant.

The findings obtained as a result of the research are important for the literature. This study reveals the importance of employees' perceptions of innovation in the context of their entrepreneurial orientation towards their organizations. For this to happen, activities must be carried out to increase the motivation of employees in organizations.

Keywords: Innovation, Entrepreneurial Orientation, Organizational Climate, Defense industry.

DOI: https://doi.org/10.29329/jtm.2020.289.1

\section{GíRiș}

Küreselleşmenin etkisi ile meydana gelen hızlı ve kapsamlı değişim süreci, tüm alanlarına etkilemiştir. Çevrede canlı bir organizma olan organizasyonlar bu değişimlerden etkilenmekte ve çevrede yaşamlarını devam ettirmek için bu değişimle mücadele etmek zorundadır.

Gelişen ve değişen ortamda faaliyet gösteren organizasyonlar bağımsız olarak ya da kurumsal sistemin parçası olarak hareket eden bireylerin oluşturduğu grup ya da birey olan girişimciler vasitasıyla, organizasyonların hayatını devam ettirmesi ve rekabet avantajı kazanması için yaratıcılık, canlanma ve yenilik olarak tanımlanan girişimcilik faaliyetinde bulunur.

Bazı organizasyonlar yenilenmeyi geleneksel girişimcilik ile yapar, bazıları bir plan ya da risk departmanı vasıtasıyla yapar, bazıları da daha az hiyerarşi olan organizasyonlar AR-GE ye, mühendise, pazarlamacıya ya da üretim departmanına yaptırabilir. Fakat burada önemli olan kimin kritik aktör olduğu değil girişimcilik sürecinin kendi kendine olması ve organizasyon faktörlerinin onu teşvik etmesi ve engellememesidir (Miller, 1983:1). Girişimcilik sürecinin olması ise organizasyonun örgüt seviyesinde girişimcilik eğilimine yani girişimcilik yönelimine sahip olması ile mümkündür.

Girişimcilik yönelimi, pazarda yeniliğe, ürünlere ve riskli projelere odaklanan yaklaşım ve yenilikçiliğin öncülüdür. Bu da yeni ürünlerin geliştirilmesi, var olan ürünlerin dönüştürülmesi, yeni üretim metodlarının veya dağıtım kanallarının yaratılması, yeni yönetim tutumlarının ve rekabet stratejilerinin bulunması ile olur (Ma'atoofi ve Tajeddini, 2010:255). Girişimcilik yönelimi; var olan kaynakların yeni yollarla geliştirilmesi ya da yeni kaynakların yaratılması ve yeni ticari ürünler, yeni 
pazarlara taşınması ya da yeni müşterilere hizmet edilmesi olan girişimciliğin özünü elde etmek için bir yapı olarak geliştirilmiştir (Morris vd., 2011:949).

Yenilikçi davranışların felsefesine adanmış üst yönetim tarafından yapılandırılan uygun içyapıya, kültür ve meşru süreç yapısına sahip olmaya bağlıdır (Guth and Ginsberg, 1990; Colvin and Slevin, 1991; Hitt vd., 1999).

Chandler vd. (2000) yaptığı çalışmada algılanan yönetim desteği ve organizasyonun ödül sisteminin, organizasyonun ve girişimcilik yöneliminin en önemli özelliği olan yenilikçiliği desteklediğini vurgulamıştır. Örgüt ikliminin yenilikçilik ve yaratıcılıkta önemli bir motivasyon aracı olduğu ve girişimciliği desteklemedeki önemi ortaya çıkmaktadır (Hayton, 2005:32).

Girişimcilik sadece uygun ortamda yaşayan bir ruhtur. Bu yüzden çalışanların girişimcilik davranışları organizasyonun inanç ve değerleri tarafından etkilenir. Bu inanç ve davranışların çalışan üzerinde etkisi pozitif bir örgüt iklimi yaratması sonucunda çalışanlar bu durumdan etkilenecek ve organizasyon bu çalışanlar vasıtasıyla firsatları takip edip yaratıcılığını artırarak çevrede lider duruma gelip amaçlarını başaracaktır (Behram ve Özdemirci, 2014:266).

Bu bilgiler ışığında söz konusu çalışma girişimcilik yönelimi boyutlarından yenilikçilik ile örgüt iklimi arasındaki ilişkiye odaklanarak, savunma sanayi çalışanları üzerinde incelenmesini amaçlamaktadır.

\section{KAVRAMSAL ÇERÇEVE}

\section{Girişimcilik Yöneliminde Yenilikçilik}

Girişim, girişimcilik ve girişimci kavramları tanımlandığında; üretim faktörlerinin bir araya getirildiği, teknik, ekonomik ve hukuki birimler girişim veya işletme, işletmeyi kuran, yönlendiren, geleceğe ilişkin planları yapan ve yürüten kişi girişimci, girişimcinin bir işletme kurmak veya üretim faktörlerini bir araya getirmeye yönelik bütün çabaları girişimcilik olarak ifade edilir (Yelkikalan vd., 2010:51).

İşletmelerin yeni pazarlara girme yeni ürün ve yeni müşterilere hizmet etmek ve pazarda pay sahibi olmak için gerçekleştirdiği girişimcilik faaliyetleri; pazar ve hareket sahasında firmaların sürekli olarak yenilenme, yenilikçilik, yapısal olarak risk alma yeteneğini sürekli olarak gerçekleştirmesini gerektirir (Tajeddini, 2010:222). Girişimcilik; özellikle firmaların dış çevresinde değişen koşullar altında stratejik yenilenmeye temel duruştur. Bu sayede firmalar rekabet avantajını geliştirir ve sonuçta daha büyük finansal ödül kazanır ve organizasyonun karlılığını da etkiler (Knight 1997:215) 
Tablo 1. Girişimciliğin ve girişimcilik yöneliminin yenilikçilik perspektifini açıklayan tanımlar

\begin{tabular}{|l|l|}
\hline $\begin{array}{l}\text { Schollhammer } \\
(1982)\end{array}$ & $\begin{array}{l}\text { Örgüt tarafından kabul gören içsel girişimcilik faaliyetleri, yenilikçi kurumsal çabalar için } \\
\text { örgütsel onay ve kaynak almakta ve yeni ürün gelişimi, ürün iyileştirmesi, yeni yöntem veya } \\
\text { süreçleri kapsamaktadır. }\end{array}$ \\
\hline $\begin{array}{l}\text { Zahra vd } \\
(2000)\end{array}$ & Bir şirkette deki girişimcilik, yenilikçilik ve yenileme çabalarının tamamı(s.947) \\
\hline $\begin{array}{l}\text { Zahra (1995, } \\
1996)\end{array}$ & $\begin{array}{l}\text { Kurumsal girişimcilik, bir işletmenin yenilik, yenilenme ve girişimcilik çabalarının toplamı } \\
\text { olarak ifade edilir. Yenilik; ürünler, üretim süreçleri ve örgütsel sistemlerin yaratılması ve } \\
\text { tanıtımını kapsamaktadır. }\end{array}$ \\
\hline $\begin{array}{l}\text { Schollhammer } \\
(1982)\end{array}$ & $\begin{array}{l}\text { İçsel üst yönetim girişimciliği, mevcut bir örgütteki girişimcilik faaliyetlerini belirtmektedir. } \\
\text { Örgüt tarafından kabul gören içsel girişimcilik faaliyetleri, yenilikçi kurumsal çabalar için } \\
\text { örgütsel onay ve kaynak almakta ve yeni ürün gelişimi, ürün iyileştirmesi, yeni yöntem veya } \\
\text { süreçleri kapsamaktadır. }\end{array}$ \\
\hline $\begin{array}{l}\text { Nielson, } \\
\text { Peters ve } \\
\text { Hisrich (1985) }\end{array}$ & $\begin{array}{l}\text { Girişimcilik yönelimi, örgütlerde dahili anlamda pazar araştırması faaliyetleri yapmak, } \\
\text { iyileştirici ve yenilikçi iş gören hizmetleri sağlamak, teknolojileri ve metotlarını genişletmek } \\
\text { için tasarlanan küçük ve bağımsı birimler ile büyük örgütlerin dahili pazarlarındaki } \\
\text { gelişmeleri ifade etmektedir. Bu harici pazarlarda karlı pozisyon elde etmek amacı taşıyan } \\
\text { kapsamlı örgüt girişimciliği/girişimi birimlerinden farklıdır. }\end{array}$ \\
\hline
\end{tabular}

Sharma P, Chrisman J.J. (1999),"Toward a Reconciliation of the Definitional Issues in the Field of Corporate Entrepreneurship" Entrepreneurship Theory And Practice, ss. 11-27.

Yenilikçiliğin girşimciliğin ve girişimcilik yöneliminin önemli boyutlarından birisi olduğunu ifade eden birçok çalışma bulunmaktadır. Bu çalışmalarda ortak özellik girişimcilik tanımının yenilikçilik perspektifinden açıklanmasıdır. Tablo 1’de söz konusu tanımlara örnekler verilmiştir.

Yenilikçilik eğilimi, girişimcilik ve girişimcilik yöneliminin en önemli, hatta olmazsa olmaz öğesidir (Covin ve Miles, 1999). Bu nedenle organizasyonların yenilikçiliği gerçekleştirecek uygun örgütsel yapıya sahip olunması gerekmektedir. Kaynaklara dayalı bakışın önemli özelliği ekonomik karlılı̆̆ın mekanizması olarak kaynakların birleşiminin yenilikle birleştirilmesine vurgu yapar yenilik ve değişimin dinamiği olarak teknoloji önemlidir. Bu sebepten girişimci organizasyonların çevredeki değişimlere cevap vermesi, yüksek yenilik etkisine sahip olması ile olur (Autio ve Yli-Renko 1998:72).

Yenilik yapmak bir süreç olarak yeni bir fikir ya da buluşun pazarlanabilir bir ürüne dönüştürülmesidir (Lumpkin ve Dess, 2005). Yenilik, "bilginin, örgütsel fonksiyonları yerine getirmek üzere, orijinal, ilintili, benzersiz çözüm ve değer yaratan yeni kaynak, ürün, süreç, hizmet, yönetim tekniği veya teknoloji biçiminde somutlaştırılarak değiştirilmesi, birleştirilmesi ya da sentezlenmesi aracılığıyla ticari değer kazanması süreci” olarak tanımlanmıştır (Altuntaş 2010:54).

Yenilikçilik birçok farklı formlarda meydana gelir. Teknolojik yenilik: yeni ürün ve süreçlerin geliştirilmesine yardımcı olan mühendislik çabalar ve araştırmanın başlangıcından oluşur. Ürün pazar yeniliği; Pazar araştırmaları, ürün dizaynı ve reklam ve tanıtım yeniliğini içerir. Yönetim yeniliği; yönetim sistemlerinde, kontrol tekniklerinde, organizasyon yapısında yeniliği ifade eder Lumpkın ve Dess 1996:143, Lumpkin ve Dess 2005:150). 
Tablo 2. Yenilikçilik Tanımları.

\begin{tabular}{|c|c|}
\hline Yazar & Yenilikçilik Tanımı \\
\hline $\begin{array}{l}\text { Lumpkin ve Dess } \\
(2001: 431)\end{array}$ & $\begin{array}{l}\text { Yenilikçilik; yaratıcılığı desteklemek için istekliliği gösterir ve yeni } \\
\text { ürün/hizmetle tanışma deneylemeleri, teknolojik liderlik ve yeni süreçler için } \\
\text { araştırma geliştirme yapmak olarak tanımlanır. }\end{array}$ \\
\hline Morris Vd. (2011:949) & $\begin{array}{l}\text { Organizasyonun duruşu açısından yenilikçilik; yeni fikirler ve } \\
\text { kombinasyonlar için örgüt kültürünün açık olması yanında yeni ürün, } \\
\text { hizmet, süreç yaratmak için yeni fikirler üretme tecrübe etme ve yani } \\
\text { faaliyetlere katılma eğilimini yansıtan organizasyon özelliğini yansıtır. }\end{array}$ \\
\hline Hosseini Vd. (2012:241) & $\begin{array}{l}\text { Yenilikçilik; yeni hizmet ve ürünleri deneme, çağdaş ürün ve süreçlerle } \\
\text { tanışma kapasitesine sahip olmadır. }\end{array}$ \\
\hline Razak (2011:252) & $\begin{array}{l}\text { Yenilikçilik yeni fikirleri, yeniliği, tecrübeleri yaratıcı fikir yada } \\
\text { araştırmaları ve yeni ürün, hizmet ya da teknolojik süreçle sonuçlanan } \\
\text { gelişim faalyetlerini destekleme, ilişkili olma eğilimidir }\end{array}$ \\
\hline $\begin{array}{l}\text { Lumpkin ve Dess } \\
(1996: 142)\end{array}$ & $\begin{array}{l}\text { Yenilikçilik; teknolojik süreç, yeni ürün ya da hizmet sonucu yaratıcı } \\
\text { süreçler, tecrübe, yenilik, yeni iddiayı desteklemek ve organizasyonun bu } \\
\text { konudaki eğilimini gösterir. Bununla birlikte yenilikçilik var olan } \\
\text { teknolojiler ya da pratiklerden ayrılma ve var olan durumun ötesindeki } \\
\text { teşebbüsleri gerektirir. }\end{array}$ \\
\hline Zahra ve Garvis (2000:471) & $\begin{array}{l}\text { Teşebbüsler sonucu yaratılan yeni ürünü başarılı bir şekilde pazarla } \\
\text { tanıştırma yeteneğidir. Organizasyonun bu süreçlere adanmasının göstergesi } \\
\text { organizasyonel yenilik olarak tanımlanır. }\end{array}$ \\
\hline $\begin{array}{l}\text { Zagra } \\
(1995: 45)\end{array}$ & $\begin{array}{l}\text { Yenilik: hâlihazırdaki ve gelecek pazarların taleplerini karşılamak için yeni } \\
\text { ürün yaratmak veya var olanı iyileştirmek için firmaların yeteneğini olarak } \\
\text { tanımlanır. }\end{array}$ \\
\hline $\begin{array}{l}\text { Pearce Vd. } \\
(2010: 225)\end{array}$ & $\begin{array}{l}\text { Yenilik; müşterin ihtiyacını temelde karşılamak için ya da faaliyetleri } \\
\text { geliştirmek için yeni kombinasyonları sürdürmek amacıyla organizasyonun } \\
\text { çabasını yansıtır. Organizasyonun; var olan teknoloji ve pratiklerden farklı } \\
\text { olarak yeni fikirleri, yeniliği, tecrübeyi desteklemek için organizasyonun } \\
\text { hazır olmasını temsil eder. }\end{array}$ \\
\hline
\end{tabular}

Tablo 2'de belirtilen tanımlar incelendiğinde yenilikçilik; organizasyonların çevreye uyum sağlama ve hayatını idame ettirmesi için var olan teknoloji ve pratiklerden farklı kombinasyonlarla ya da yeni bilgiyi elde ederek yeni ürün hizmet ortaya çıkarmak için organizasyonun eğilimini gösterir.

Yazın araştırmalarında görüldügü gibi organizasyonlarda yenilikçilik kavramı girişimcilik ile ilgili kavramlarla vücut bulmakta ve bu eylemin gerçekleşmesi risk alma ve öngörülü olmay gerektirmektedir. Aynı zamanda bu üç kavram birbirlerini karşılıklı olarak etkilemektedir (Covin ve Slevin 1991:7).

$\mathrm{Bu}$ faaliyetler firmaların yenilenmesini sağlar. Yenilenme genellikle yenilik ve girişim faaliyetleri boyunca başarılabilir. Farklı yetenekler, kapasiteler ve kaynaklara ulaşmayı sağlar. Yenilikçilik; organizasyonlara, büyümeyi ve karlılığı başarmayı, yeni rekabetçi yaklaşımları geliştirmeye izin veren organizasyonun bilgi deposunu gözden geçirtir (Zahra ve Garvis 2000:471). Bunun sonucu olarak çeşitli bilgi kaynağına ulaşan organizasyonlar önemli öğrenme firsatı yakalayarak yenilikçilik vasıtasıyla süreç yeniliği yapar. Süreç yeniliği teknolojik süreçleri iyileştirmeye ya da yeni hizmet, yeni ürünün sonucu 
tecrübe ve yaratıc1lığa katılmayı sağlar. Bunu gerçekleştirmek için hâlihazırdaki durumun ötesinde teknoloji, teşvik ve pratiğe ihtiyaç vardır (Lumpkın ve Dess 2005:150).

Organizasyonlarda yenilikçiliğin ortaya çıkabilmesi, teşvik ve pratiğin sağlanmasının temel kriteri organizasyonda hâkim olan psikoloji ortam koşulları ve bu ortam koşularının yarattığı ilişkiler bütünü ile mümkün olacaktır. Bütün bu kavramlar ise örgüt iklimi ile açıklanmaktadır. Organizasyonlar çalışanlarını yaratıcı ve yenilikçi olun diye zorlayamaz sadece bunun için çalışanlara ilham verir ve motive eder bu ise örgüt iklimi ile olur (Wannapa, 2014:126). Genç ve Karcığlu (2000) çalışmasında belirttiği gibi örgüt iklimi; örgütün iç çevresinin organizasyon üyeleri tarafından algılanması ve yorumlanması sonucu paylaşılan algılar neticesinde organizasyonları tarif eden bilişsel temsiliyet olarak tanımlanır. Bu algı "bireylerin davranışlarını etkileyen ve onlardan etkilenen, somut olarak gözle görülüp elle tutulamayan, ancak örgüt, içindeki bireylerce hissedilip algılanabilen” algıdır (Aktaran: Yüceler, 2009:447).

\section{Örgüt İklimi}

Örgüt iklimi; organizasyon üyelerinin psikolojik algısının toplamının sonucu olarak bulunduğu zamanı temsil eder ve organizasyonun kararlı değişmez ve sürekli niteliğine sahiptir. Bu niteliği ile Örgüt iklimi bilgi yönetiminin algısını etkileyen ve çalışanların davranışını şekle sokmada önemli rol oynar. Organizasyonların rekabet avantajının devamının kilit rollerinden biri iç süreçler, yetenekler, prosedürlerdeki hareket seti için sürekli yenilik iklimini teşvik etmesi ile gerçekleştirilir (Merrifield, 2000:41).

Örgüt iklimi; organizasyonlarda serbest düşünme, fikirlerini ve iddialarını açıkça ifade etmek ve yenilik iklimi boyunca rutin olmayan alternatiflerin açığa çıkması için organizasyon üyelerini cesaretlendirir ve organizasyon üyeleri arasında sosyal etkileşimi artırır (Chen ve Huang, 2007:105). Kişinin iklimi destekleyici, cesaretlendirici olarak algılaması davranışlarını pozitif yönde etkilemektedir (Çekmecelioğlu, 2006:299). Bu da organizasyonda pozitif örgüt iklimi oluşturacaktır. Pozitif örgüt iklimi organizasyon üyelerinin motivasyonunun ve görevdeki çabasının artırılması neden olacaktır (Neal vd., 2005: 496). Dinamik çevrede örgüt iklimi; değişimi ve girişimi kolaylaştıracaktır (McGuinness, 2005:1315).

Yazın incelendiğinde örgüt ikimi ile ilgili farklı çalışmalarda 80 den fazla örgüt iklimi boyutlarına rastlanmaktadır. Schneider, Brief and Guzzo (1996) organizasyon iklimini dört boyut olarak tanımlanmıştır. Söz konusu boyutlar şu şekilde sıralanabilir; (a) çalışanların kendi içlerindeki ilişkilerin doğası, (b) hiyerarşinin doğası, (c) işin doğası, (d) destek ve ödüle odaklanma (Schneider vd. 1996:10).

Bir diğer sınıflamada, Yahyagil (2001, 2003) tarafından Litwin'in yaklaşımı (Litwin ve Stringer, 1968) esas kabul edilerek ve ayrıca Schneider, Brief ve Guzzo (1996) ile bu alanın öne çıkan sosyal bilimcilerinin (Fey ve Beamish, 2001; Kirsh, 2000; Jones ve James, 1979) çalışmaları dikkate alınarak 
Türkiye'de örgüt iklimi boyutunu, biçimselleştirme, destek, işin doğası, ödül, insanlar arası ilişki, risk alma, iletişim, yenilik, karar alma, takım çalışması olarak on boyutlu olarak geliştirilmiştir (Yahyagil, 2006:100).

Yukarıda görüldügü gibi farklı yazarlar tarafından organizasyonda örgüt iklimini belirlemede çalışmanın özelliğine göre farklı değişkenler ele alınmıştır. Bu çalışmada örgüt ikliminin temel bileşenleri: bağ kurma (affiliation), adalet (Fairness), iletişim (communication) olarak alınmıştır.

\section{YÖNTEM}

Günümüz iş dünyasında küreselleşme ile birlikte teknolojinin hızlı bir şekilde değişmesi ve gelişmesi dışa açık sistem olan organizasyonlar ortaya çıkan bu durumlardan hızlı bir şekilde etkilenmektedir. Bu değişim rüzgârından etkilenen organizasyonlar çevrede ayakta kalabilmek, amaçları gerçekleştirmek ve çevreyle mücadele etmek için bilgiye ihtiyacı vardır. Bunun için günümüzde açık bir sistem olan organizasyonların öğrenmeye ve bunun ile ilgili özelliklere sahip olmaya, sürekli kendini yenilemeye ve geliştirmeye ihtiyacı vardır.

Bu yenileme ve geliştirme süreci, sürekli yenilikçilik ile gerçekleşeceği varsayımından hareketle bu çalışmanın amacı girişimcilik yöneliminin önemli boyutlarından birisi olan yenilikçilik perspektifinin örgüt iklimi ile olan ilişkisinin savunma sanayi çalışanları üzerinde incelenmesidir.

Girişimcilik yönelimi ve örgüt iklimi arasındaki ilişkiyi ortaya koymak için yazın incelendiğinde, örgüt iklimi ile yakından ilgili olan güçlendirme, ödül, yönlendirme, çatışma çözümü, kimlik, bireysel girişimcilik, risk toleransı, bütünleşme, iletişsim yönetici desteği arasındaki ilişkiyi incelemiş ve bu faktörlerin yüksek olmasının yüksek organizasyon seviyesi girişimciliğe sebep olacağını bu da girişimcilik yönelimini artıracağı sonucuna varılmaktadır (Sepehri ve Khayati 2013:147). Organizasyon iklimi ile organizasyon stratejinin uyumlu olması gerektiğini göstermiştir (Burton vd., 2004:80). Ireland vd (2009) makalesinde iklimin alt boyutlarından olan ödül sisteminin girişimciliği cesaretlendirdiğini ifade etmiştir (Ireland vd., 2009:32). Masomi vd. (2013) yaptığı organizasyon iklim boyutları ve üst yönetim girişimciliği arasındaki ilişki adlı makalede örgütsel iklim ve üst yönetim girişimciliği arasında anlamlı ve pozitif ilişki bulmuşlardır. Rangriz (2012) örgüt iklimi, organizasyon girişimciliği ve belirsizlik toleransı üzerine yaptığı deneysel çalışmada organizasyon girişimciliği ile organizasyon iklimi arasında önemli bir ilişski bulmuştur. Çalışmalar gösteriyor ki örgüt ikliminin, girişimcilik yöneliminin yenilikçilik boyutu ile ilişkisine yönelik araştırmalar yeterli düzeyde değildir. Bu bağlamda ilgili ilişkinin incelenerek sonuçların ortaya konulması önemlidir. Bu bilgilerden hareketle araştırma hipotezleri şu şekilde oluşturulmuştur; H1: Çalışanların algıladıkları örgüt iklimi; girişimcilik yönelimi bağlamında yenilikçilik düzeyini pozitif ve anlamlı olarak etkiler.

H2: Çalışanların algıladıkları bağ kurma düzeyi; yenilikçilik düzeyini pozitif ve anlamlı olarak etkiler. 
H3: Çalışanların algıladıkları adalet düzeyi; yenilikçilik düzeyini pozitif ve anlamlı olarak etkiler.

H4: Çalışanların algıladıkları iletişim düzeyi; yenilikçilik düzeyini pozitif ve anlamlı olarak etkiler.

Araştırma nicel tekniklerden anket yöntemi ile gerçekleştirilmiştir. Girişimcilik yönelimi boyutlarından yenilikçilik perspektifinin ölçülmesi için girişimcilik yönelimini tek boyutlu olarak üç faktörün kullanılması daha iyi sonuçlar vereceği değerlendirildiğinden Covin ve Slevin (1989)'inin geliştirdiği ölçek kullanılmıştır. Covin ve Slevin (1989) tarafından geliştirilen ölçek 3 boyut ve her boyut 3 madde olacak şekilde toplam 9 maddeden oluşmaktadır. Bu boyutlar yenilikçilik (GY), öngörülülük (GO) ve risk alma (GR) şeklindedir. Ölçekte cevaplar 5'li likert ölçeği ile alınmıştır (1=Kesinlikle katılmıyorum, 5=Kesinlikle katılıyorum). Covin ve Slevin (1989) ölçeğin Cronbach alfa güvenirlik katsayısını 0,87 olarak belirlemiştir.

Diğer yandan çalışanların algıladıkları örgüt iklimini belirlemek üzere Bock vd. (2005) tarafindan yapılan çalışmada kullanılan örgüt iklimi ölçeği kullanılmıştır. Çalışmamızda yenilik boyutu girişimcilik yöneliminin alt boyutunda kullanıldığından yenilik alt boyutu kullanılmayarak bağ kurma, adalet olarak iki alt boyut Bock vd. (2005) çalışmasından alınmıştır. Coda vd. (2015) çalışmasında kullandığı örgüt iklimi boyutlarından iletişim alt boyutu alınmıştır. Örgüt iklimi ölçenin boyutları; Bağ Kurma $(0,898)$, Adalet $(0,870)$ ve İletişim $(0,786)$ olarak belirlenmiştir.

Ölçek 15 soru ile 3 boyutu ölçümlemek üzere yapılandırılmıştır. Ölçek; 4 madde bağ kurma, 3 madde adalet ve 8 madde iletişim olmak üzere toplam 15 maddeden oluşmaktadır. Ölçekte cevaplar 5'li likert ölçeği ile alınmıştır (1=Kesinlikle katılmıyorum, 5=Kesinlikle katılıyorum).

Araştırmanın evrenini Ankara'da faaliyet gösteren savunma sektörü çalışanları oluşturmaktadır. Araştırmanın örneklemini savunma sektörü çalışanları arasından olasılıklı olmayan örnekleme yöntemi ile seçilen denekler oluşturmaktadır. Bu işletmelerde 10 bin kişiden fazla çalışan bulunmaktadır. Ana kütleden \%95 güvenilirlik sınırları içerisinde $\% 5$ 'lik bir hata payı dikkate alınarak örneklem büyüklüğü 384 kişi olarak hesap edilmiştir (Sekaran, 1992:53). Bu kapsamda kota örnekleme yöntemiyle seçilen toplam 1000 kişiye anket uygulaması yapılması planlanmıştır. Gönderilen anketlerden 496'sı geri dönmüş ve 456 tanesi analiz yapmak için uygun bulunmuştur. Yapılan uç değer analizinde değişkenlere ait normal dağılımı bozan 8 veri seti çıkartılmış ve 448 katılımıının doldurduğu anket analizlere dâhil edilmiştir.

\section{Analiz ve Bulgular}

Girişimcilik yönelimi ölçeğinin yapı geçerliliğini test etmek maksadıyla öncelikle keşfedici faktör analiz yapılmıştır. Söz konusu kavramların veri tarafından doğrulup doğrulanmadığı tespit etmek için doğrulayıcı faktör analizi (DFA) yapılmıştır. Fakat elde edilen bulgular tek boyut göstermesi nedeniyle ölçek bazı hipotez testleri için tek boyut olarak ele alınmış ancak orijinal yapıyı korumak maksadıyla 
DFA yapılarak analize devam edilmiştir. Analiz sonucunda verilerin ölçeğin modifikasyona gerek kalmaksızın doğal kovaryanslarıyla 3 faktörlü yapısına uyum sağladığı belirlenmiştir. Tek boyutta ele alınan analizde de tüm maddeler tek boyutta toplanmıştır. Ölçeğin KMO analiz sonucu tüm boyutlar ve toplam ölçek için 0,94, Barlett testi anlamlı $(\mathrm{p}=.000)$ ve açıklanan varyans 0,71 olarak tespit edilmiştir. Ölçeğin uyum iyiliği değerleri Tablo 3'de sunulmuştur. Yapılan güvenirlik analizi sonucunda Girişimci yönelimi ölçeğinin Cronbach alfa güvenirlik katsayısı; Yenilikçilik (GY), Öngörülülük (GO) ve risk alma için sırasıyla $0,87,0,92,0,83$ olarak bulunmuştur.

Ölçeğe ilişkin Tablo 3'deki değerler göz önüne alındığında Ki-kare değeri X²/df = 63,48/ $24=$ 2,6 olarak tespit edilmiştir. Uyum kriterleri içerisinde söz konusu değerin karşıllı̆ı mükemmel uyum olarak ifade edilmektedir. Diğer yandan ilgili ölçeğe ait Uyum İyiliği İndeksi (GFI) 0,97 olarak tespit edilmiştir. İlgili tablo incelendiğinde söz konusu değerin $\geq 0,90$ olması mükemmel uyumu ifade etmektedir. İfadeden de anlaşılacağı üzere söz konusu değer mükemmel uyum aralığındadır. Buna ilave olarak ilgili ölçek için yapılan analizler sonucu Karşılaştırmalı Uyum İndeksi (CFI) değeri 0,98 olarak belirlenmiştir. Söz konusu değer için $\geq 0,97$ değeri mükemmel uyumu, $\geq 0,90$ ise kabul edilebilir uyumu ifade etmektedir. Söz konusu değer kabul edilebilir mükemmel uyum değerleri sınırındadır. Son olarak Yaklaşık Hataların Kare Kökü (RMSEA) değeri 0,06 ile kabul edilebilir sınırlar içerisindedir. Sonuç olarak söz konusu ölçek için yapılan uyum iyiliği kabul edilebilir düzeyde tespit edilmiştir. Ölçeğin birinci düzey model faktör analizi Şekil 1'de sunulmuştur.

Tablo 3: Doğrulayıcı faktör analizi sonucunda ölçeklerin uyum iyiliği değerleri

\begin{tabular}{|c|c|c|c|c|c|c|c|c|c|}
\hline Değişkenler & $X^{2}$ & df & $\begin{array}{l}\text { CMIN/ } \\
\text { DF } \\
\leq 5\end{array}$ & $\begin{array}{l}\text { GFI } \\
\geq .85\end{array}$ & $\begin{array}{l}\text { AGFI } \\
\geq .80\end{array}$ & $\begin{array}{l}\text { CFI } \\
\geq .90\end{array}$ & $\begin{array}{l}\text { NFI } \\
\geq .90\end{array}$ & $\begin{array}{l}\text { TLI } \\
\geq .90\end{array}$ & $\begin{array}{l}\text { RMSEA } \\
\leq .08\end{array}$ \\
\hline Girişimcilik yönelimi (2.düzey) & 63,48 & 24 & 2,6 & 0.97 & 0.94 & 0.98 & 0.98 & 0.98 & 0.06 \\
\hline
\end{tabular}

Not: Uyum iyiliği değer aralıkları "kabul edilebilir “ standartlara göre düzenlenmiștir. 


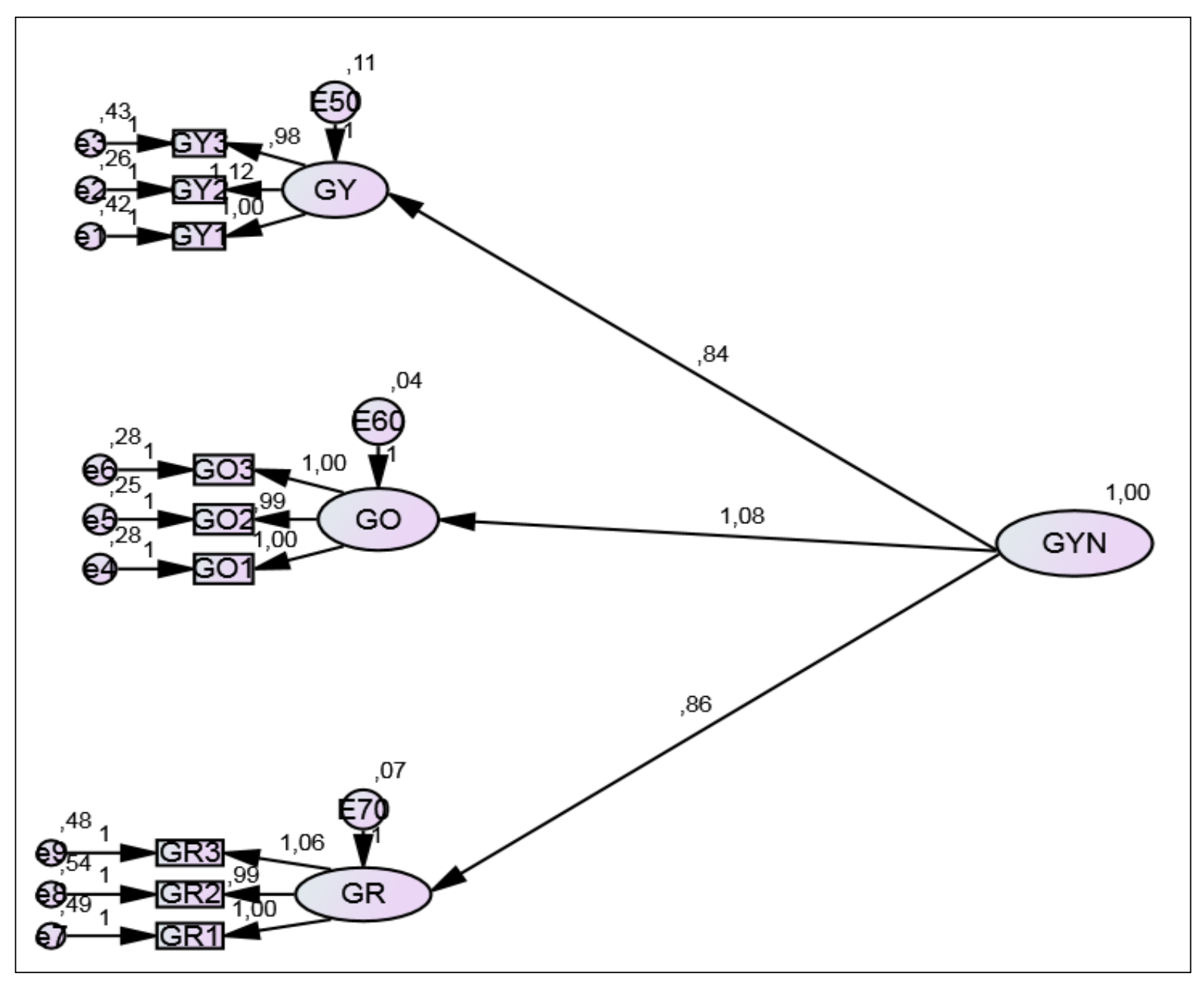

Şekil 1: Girişimcilik yönelimi ölçeği DFA sonuçları.

Örgüt iklimi ölçeğinin yapı geçerliliğini test etmek maksadıyla öncelikle keşfedici faktör analiz yapılmıştır. Analiz sonucunda verilerin ölçeğin 3 faktörlü yapısına uyum sağladığı belirlenmiştir. Bazı hipotezleri test etmek üzere ölçek tek boyutta da irdelenmiştir. Tek boyutta ele alınan analizde de tüm maddeler tek boyut altında toplanmıştır. Ölçeğin KMO analiz sonucu tüm boyutlar ve toplam ölçek için 0,70 ve üstüdür, Barlett testi anlamlıdır $(\mathrm{p}=.000)$ ve açılanan varyans 3 boyut için 0,74 , tek boyut için ise 0,61 olarak tespit edilmiştir. KFA sonuçları ve açıklanan varyanslar Tablo 4 ve 5 da sunulmuştur. $\mathrm{Bu}$ analizlerin ardından AMOS paket programı ile doğrulayıcı faktör analizi yapılmıştır. Faktör analizi sonucunda verilerin ölçeğin 3 faktörlü yapısına uyum sağladığı tespit edilmiştir. Ölçeğin uyum iyiliği değerleri Tablo 4'de sunulmuştur. Yapılan güvenirlik analizi sonucunda örgüt iklimi ölçeğinin Cronbach alfa güvenirlik katsayısı; bağl1lık (IB), adalet (IA) ve iletişim (II) için sırasıyla 0,91, 0,86, 0,93 olarak bulunmuştur. 
Tablo 4: Döndürülmüş Faktör matrisi

\begin{tabular}{|c|c|c|c|}
\hline \multirow{2}{*}{} & \multicolumn{3}{|c|}{ Bileşenler } \\
\hline & 0,787 & & $\mathbf{3}$ \\
\hline II4 & 0,739 & & \\
\hline II5 & 0,736 & & \\
\hline II6 & 0,729 & & \\
\hline II8 & 0,727 & & \\
\hline II7 & 0,718 & & \\
\hline II2 & 0,696 & & \\
\hline II3 & 0,606 & 0,846 & \\
\hline II1 & & 0,812 & \\
\hline IB1 & & 0,767 & \\
\hline IB2 & & 0,761 & 0,797 \\
\hline IB4 & & & 0,779 \\
\hline IB3 & & & \\
\hline IA1 & & & \\
\hline IA3 & & & \\
\hline IA2 & & & \\
\hline
\end{tabular}

Yapılan analiz sonuçlarına ilişkin ölçeğin uyum iyiliği değerleri Tablo 4'de gösterilmiştir. Kikare değeri $X^{2} / d f=287,6 / 87=3,3$ olarak tespit edilmiştir. Uyum kriterleri içerisinde söz konusu değerin karşıllığı kabul edilebilir uyum olarak ifade edilmektedir. Diğer yandan ilgili ölçeğe ait Uyum İyiliği Indeksi (GFI) 0,92 olarak tespit edilmiştir. İlgili tablo incelendiğinde söz konusu değerin $\geq 0,90$ olmas1 mükemmel uyumu ifade etmektedir. İfadeden de anlaşılacağı üzere söz konusu değer mükemmel uyum aralığındadır. Buna ilave olarak ilgili ölçek için yapılan analizler sonucu Karşılaştırmalı Uyum İndeksi (CFI) değeri 0,96 olarak belirlenmiştir. Söz konusu değer için $\geq 0,97$ değeri mükemmel uyumu, $\geq 0,90$ ise kabul edilebilir uyumu ifade etmektedir. Söz konusu değer kabul edilebilir mükemmel uyum değerleri sınırındadır. 
Tablo 5: Toplam Açıklanan Varyans Tablosu

\begin{tabular}{|c|c|c|c|c|c|c|}
\hline Component & \multicolumn{3}{|c|}{ Initial Eigenvalues } & \multicolumn{2}{c|}{ Rotation Sums of Squared Loadings } \\
\hline & Total & $\begin{array}{c}\text { \% of } \\
\text { Variance }\end{array}$ & Cumulative \% & Total & $\begin{array}{c}\text { \% of } \\
\text { Variance }\end{array}$ & $\begin{array}{c}\text { Cumulative } \\
\text { \% }\end{array}$ \\
\hline 1 & 9,195 & 61,300 & 61,300 & 4,994 & 33,293 & 33,293 \\
\hline 2 & 1,254 & 8,361 & 69,661 & 3,446 & 22,976 & 56,268 \\
\hline 3 & 0,735 & 4,900 & 74,562 & 2,744 & 18,293 & 74,562 \\
\hline 4 & 0,515 & 3,434 & 77,995 & & & \\
\hline 5 & 0,425 & 2,831 & 80,826 & & & \\
\hline 6 & 0,418 & 2,789 & 83,615 & & & \\
\hline 7 & 0,391 & 2,606 & 86,221 & & & \\
\hline 8 & 0,349 & 2,323 & 88,544 & & & \\
\hline 9 & 0,312 & 2,077 & 90,621 & & & \\
\hline 10 & 0,286 & 1,906 & 92,527 & & & \\
\hline 11 & 0,271 & 1,808 & 94,334 & & & \\
\hline 12 & 0,246 & 1,642 & 95,977 & & & \\
\hline 13 & 0,234 & 1,562 & 97,539 & & & \\
\hline 14 & 0,208 & 1,384 & 98,923 & & & \\
\hline 15 & 0,161 & 1,077 & 100,000 & & & \\
\hline
\end{tabular}

Extraction Method: Principal Component Analysis.

Son olarak Yaklaşık Hataların Kare Kökü (RMSEA) değeri 0.07 ile kabul edilebilir sınırlar içerisindedir. Sonuç olarak söz konusu ölçek için yapılan uyum iyiliği kabul edilebilir düzeyde tespit edilmiştir. Ölçeğin birinci düzey model faktör analizi Şekil 2'de sunulmuştur.

Tablo 6: Doğrulayıcı faktör analizi sonucunda ölçeklerin 2. Düzey uyum iyiliği değerleri

\begin{tabular}{|l|c|c|c|c|c|c|c|c|c|}
\hline & $\mathbf{X}^{\mathbf{2}}$ & $\mathbf{d f}$ & $\begin{array}{c}\text { CMIN/ } \\
\text { DF } \\
\mathbf{5}\end{array}$ & $\begin{array}{c}\text { GFI } \\
\mathbf{2 . 8 5}\end{array}$ & $\begin{array}{c}\text { AGFI } \\
\mathbf{2 . 8 0}\end{array}$ & $\begin{array}{c}\text { CFI } \\
\mathbf{2 . 9 0}\end{array}$ & $\begin{array}{c}\text { NFI } \\
\mathbf{2 . 9 0}\end{array}$ & $\begin{array}{c}\text { TLI } \\
\mathbf{2 . 9 0}\end{array}$ & $\begin{array}{c}\text { RMSEA } \\
\leq . \mathbf{0 8}\end{array}$ \\
\hline 1. Örgüt iklimi ölçeği(2. Düzey) & 287,6 & 87 & 3,3 & 0,92 & 0,89 & 0,96 & 0,94 & 0,95 & 0,07 \\
\hline
\end{tabular}

Not: Uyum iyiliği değer aralıkları “kabul edilebilir “ standartlarlara göre düzenlenmiştir. 


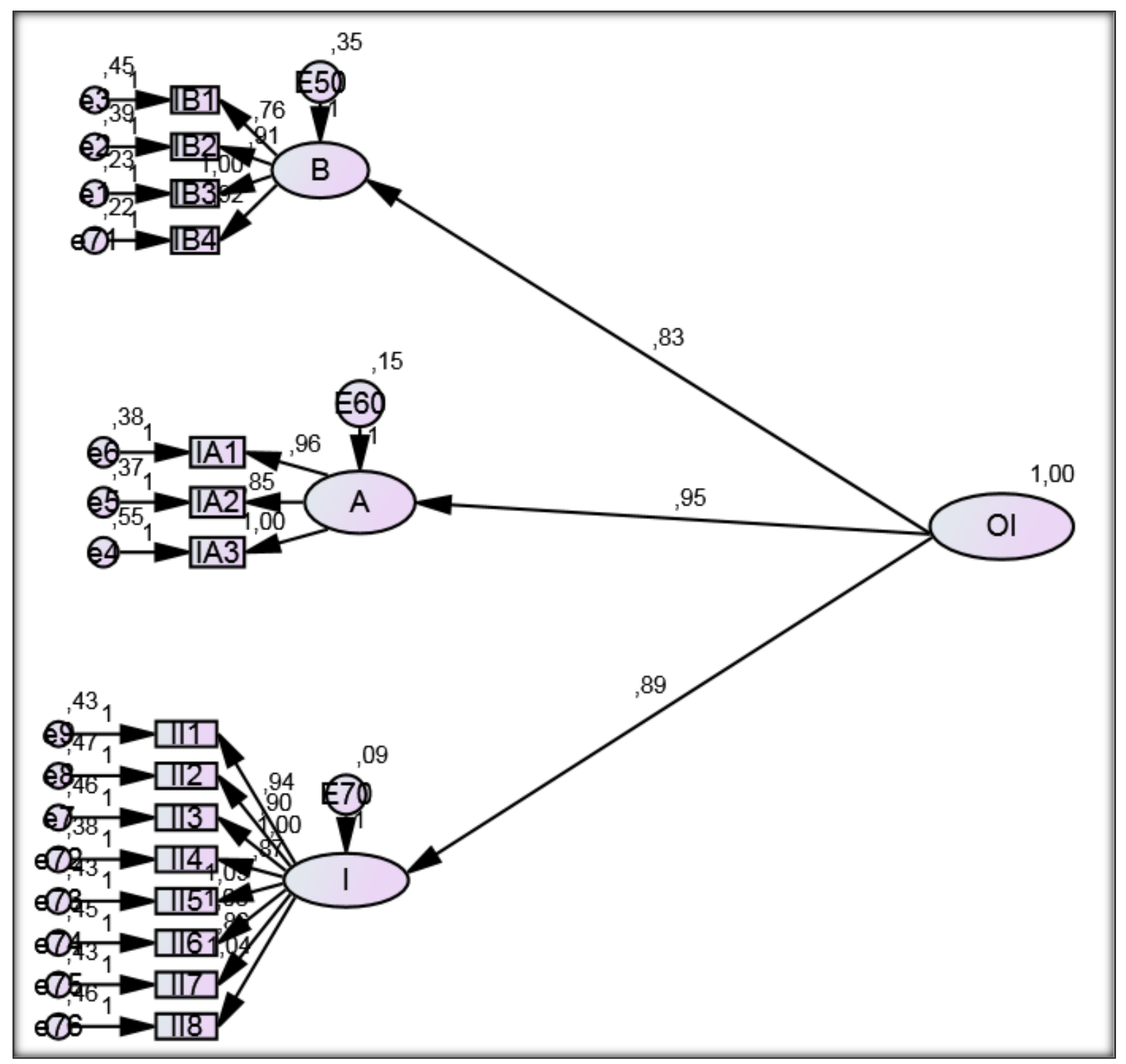

Şekil 2: Örgüt İklimi Ölçeği DFA sonuçları

Değişkenler arasındaki ilişkileri belirlemek amacıyla Pearson korelasyonları hesaplanmış olup Tablo 7'de gösterilmiştir. Tablo 7'de sunulan analiz sonuçları incelendiğinde; örgüt iklimi girişimcilik yönelimi ve öğrenme yönelimi arasında anlamlı ilişkiler görülmektedir. 
Tablo 7: Ortalama, S. Sapma ve Korelasyon Değerleri

\begin{tabular}{|l|c|c|c|c|c|c|c|c|}
\hline Değişkenler & Ort. & S.S & $\mathbf{1}$ & $\mathbf{2}$ & $\mathbf{3}$ & $\mathbf{4}$ & $\mathbf{5}$ & $\mathbf{6}$ \\
\hline GYN & 2,87 & 0,98 & & & & & & \\
\hline GY & 2,77 & 0,99 & 0,92 & & & & & \\
\hline IB & 2,81 & 0,96 & 0,65 & 0,64 & & & & \\
\hline IA & 2,73 & 1,03 & 0,65 & 0,62 & 0,60 & & & \\
\hline II & 2,73 & 0,93 & 0,72 & 0,67 & 0,68 & 0,66 & & \\
\hline OIK & 2,75 & 0,88 & 0,75 & 0,71 & 0,70 & 0,69 & 0,82 & \\
\hline
\end{tabular}

Not: Alfa güvenilirlik katsayıları parantez içinde gösterilmiştir. Tüm korelasyonlar $\mathrm{p} \leq 01$ seviyesinde (**) anlamlıdır.

Değişkenler arası doğrudan ilişkileri, diğer bir ifade biçimi ile bağımsız değişken (örgüt iklimi) bağımlı değişken (girişimcilik yönelimi bağlamında Yenilikçilik) ile ilişkileri ve aralarındaki etkileşim aşağıda sunulmuştur. Analizler yapılırken ilk adımda cinsiyet, yaş, eğitim ve çalışma süreleri kontrol altına alınmış ikinci adımda bağımsız değişken analize dahil edilmiştir.

Hipotezleri test etmek maksadıyla yapılan analiz sonuçları değerlendirildiğinde, Tablo 8'da da görüldüğ̈̈ üzere $\mathbf{H 1}$ desteklenmiştir.

Tablo 8: Örgüt İklimi ile Girişimcilik Yönelimi Arasındaki İlişkiye Yönelik Regresyon Analizi Sonuçları

\begin{tabular}{|l|c|c|c|}
\hline \multicolumn{4}{|c|}{ Girişimcilik yönelimi } \\
\hline Değişkenler & \multicolumn{2}{|c|}{$\boldsymbol{\beta}$} & \\
\hline & Adım 1 & Adım 2 & Sonuç \\
\hline Cinsiyet &, 08 &, 04 & \\
\hline Yaş &, $19^{*}$ &, 08 & \\
\hline Eğitim &, 04 &, 04 & \\
\hline Çalışma süresi &, 06 &, 01 & \\
\hline Örgüt iklimi & &, $74^{* * *}$ & H1 \\
\hline$F$ & $3,5^{* *}$ & $116,99^{* * *}$ & \\
\hline$\Delta R^{2}$ &, 03 &, 53 & \\
\hline
\end{tabular}

${ }^{*} p \leq .05, * * p \leq .01, * * * p \leq .001, \sqrt{ }$ : Desteklendi, $\downarrow$ : Desteklenmedi

Hipotezleri test etmek maksadıyla yapılan analiz sonuçları değerlendirildiğinde, Tablo 9'da görüldüğü üzere H2, H3 ve $\mathbf{H 4}$ desteklenmiştir. 
Tablo 9: Yenilikçilik ile Örgüt İklimi boyutlarının "Bağ Kurma”, "Adalet”, "İletişim” Arasındaki İlişkiye Yönelik Regresyon Analizi Sonuçları

\begin{tabular}{|c|c|c|c|c|c|c|c|}
\hline & \multicolumn{7}{|c|}{ Yenilikçilik } \\
\hline & \multicolumn{7}{|c|}{$\beta$} \\
\hline & Adım 1 & Adım 2 & Adım 1 & Adım 2 & Adım 1 & Adım 2 & Sonuç \\
\hline Cinsiyet &, 03 & ,005 &, 03 &, 01 & ,03 & ,01 & \\
\hline Yaş &, $20 * *$ &, 10 &, $20 * * *$ &, $13 * *$ &, $20 * * *$ & ,13 & \\
\hline Eğitim &, 06 &, $01 *$ &, 01 &, 03 &, 01 & ,006 & \\
\hline Çal.Sure & 05 &, 02 &, 05 & ,01 &, 05 &, 05 & \\
\hline Bağ kur. & &, $62 * * *$ & & & & & H2a $\sqrt{ }$ \\
\hline Adalet & & & &, $61 * * *$ & & & H3a $\sqrt{ }$ \\
\hline İletişim & & & & & &, $65 * * *$ & H4a $\sqrt{ }$ \\
\hline$F$ & $3,7 * *$ & $64,3 * * *$ & $3,7 * *$ & $59,3 * * *$ & $3,7 *$ & $73,7 * * *$ & \\
\hline$\Delta R^{2}$ & 03 &, 38 & ,03 & ,36 & ,03 & ,42 & \\
\hline
\end{tabular}

${ }^{*} p \leq .05, * * p \leq .01, * * * p \leq .001, \sqrt{ }$ : Desteklendi, $\downarrow$ : Desteklenmedi

Hipotezleri test etmek maksadıyla yapılan analiz sonuçları değerlendirildiğinde, Tablo 10'da da görüldüğ̈̈ üzere H1, H2, H3 ve H4, desteklenmiştir.

Tablo 10: Hipotez Test Sonuçları

H1: Çalışanların algıladıkları örgüt iklimi Girişimcilik Yönelimi bağlamında yenilikçilik düzeyini pozitif ve anlamlı olarak etkiler

DESTEKLENDİ

H2: Çalışanların algıladıkları bağ kurma düzeyi yenilikçilik düzeyini pozitif ve anlamlı olarak etkiler

H3: Çalışanların algıladıkları adalet düzeyi yenilikçilik düzeyini pozitif ve anlamlı olarak etkiler

H4: Çalışanların algıladıkları iletişim düzeyi yenilikçilik düzeyini pozitif ve anlamlı olarak etkiler

DESTEKLENDI

DESTEKLENDI

DESTEKLENDi

\section{Sonuç ve Değerlendirme}

Teknolojide meydana gelen hızlı değişim nedeni ile organizasyonlar hızlı bir değiş̧im ve dönüşüm içerisindedir. Bu değişen ve gelişen ortamda açık sistem olan bugünün organizasyonları varlıklarını sürdürebilmek için dinamik olmak zorundadır. Bunu gerçekleştirmek için başlangıçta organizasyonun iç yapısını dizayn ederken; girişimcilik yönelimi bağlamında yenilikçi mekanizmalar oluşturulmalıdır. Organizasyonlarda bu mekanizmaları harekete geçirecek en önemli kaynak insan gücüdür. Organizasyonlar; bu insan gücünü bu vizyon ve misyon anlayışında işe alıp organizasyon üyelerinin motivasyonunu sağlanmasında en önemli unsur olan uygun örgüt iklimi gerçekleştirmek için örgüt kültürünü sağlam temeller üzerine inşa etmesi gerekmektedir.

Bu çalışmada savunma sanayisinde girişimcilik yönelimi bağlamında yenilikçilik ve örgüt iklimi arasındaki ilişki incelenmiştir. Bu konular ile ilgili alan yazın incelenmiş ve yazında tespit edilen 
boşlukları kapatacağı değerlendirilen ve yazına katkı sağlayacağı düşünülen girişimcilik yönelimi bağlamında yenilikçilik ve örgüt iklimi ilişkisini gösteren toplamda dört hipotez ileri sürülmüştür.

Başlangıçta bu değişkenleri ölçen ölçeklerin yapı geçerliliğini test etmek için keşfedici, doğrulayıcı ve yapısal eşitlik modeli ile faktör analizleri yapılmış ölçeklere ait tüm veriler iyi uyum iyiliği gösterdiği ve yapılan güvenirlik analizi sonucunda ölçeklerin güvenilirliği iyi seviyede tespit edilmiştir. Daha sonra çalışmanın hipotezleri; yapılan istatistiki analizler sonucunda bu değişkenler arasındaki ilişkinin gücü korelasyon testine tabi tutulmuş ve bu ilişkinin etkisi regresyon analiz yapılıp ortaya çıkarılmıştır. Bu analizler neticesinde girişimcilik yönelimi bağlamında yenilikçilik ile örgüt iklimi değişkeni ve örgüt ikliminin alt boyutları arasında yapılan analiz sonucu pozitif ve anlamlı bir ilişki olduğu tespit edilmiştir. Bu ilişki yazında yapılan araştırmalarla tutarlılık gösterdiği görülmüştür (Sepehri ve Khayati 2013:147, Burton vd. 2004:80, Ireland vd. 2009:32, Masomi vd. 2013, Rangriz 2012:101).

Girişimcilik yönelimi bağlamında yenilikçilik, riskli projelere girmeyi, rekabette öncü olmayı vurgular ve yönetimin stratejik niyeti ve operatif faaliyetleri arasında uyumun devam ettirilmesini ifade eder. Bunula birlikte girişimcilik yönelimi, arzu edilen davranışları destekleyen ve cesaretlendiren iç çevreninin ve uygun davranışların yaratılmasıdır. Burada bahsedilen arzu edilen davranışlar örgüt iklimini yansıtmakta olup örgüt ikliminin yenilikçilik faaliyetleri ile uyumlu olması durumunda organizasyon başarıya ulaşacağı değerlendirilmektedir. $\mathrm{Bu}$ sebeple organizasyonun en önemli kaynaklarından biri olan insan kaynağına önem verilmeli örgüt iklimini güçlendirecek mekanizmaları kurulmalıdır. Değişen durumlara uyum sağlayacak şekilde değişen ve gelişen organizasyon yapısına uygun yeni mekanizmaların önceden tespit edilip organizasyonun yapısına uyarlanması gerekmektedir. Başlangıçta üst yönetim kademesi olmak üzere diğer yönetimin kademeleri ve organizasyon üyelerinin bu konularda hassasiyet göstermesi önemlidir.

Görüldüğü üzere; organizasyonlarda girişimcilik yönelimi bağlamında yenilikçiliğin başarılması için organizasyon üyelerinin girişimcilikle ilgili psikolojik algısını oluşturan olumlu bir iklimin oluşturulması önemlidir. Bunun için dinamik ve değişken çevrede faaliyet gösteren organizasyonların rekabet avantajı kazanması ve hedeflerini gerçekleştirmesi için organizasyonlarda olumlu iklim yaratmak için çaba göstermesi gerekmektedir (Halis ve Uğurlu, 2008:119).

Savunma sanayii firmaları ileri teknoloji ürünler tasarlayan ve kendilerini sürekli yenileyen firmalar olduğundan çevrede lider organizasyon olmak için meydana gelen değişimleri yakından takip etmelidir. Aynı zamanda bu faaliyetleri gerçekleştirecek nitelikli, yetişmiş insan gücünü elinde bulundurmalı ve bu faaliyetlerin başarılması için uygun örgüt iklimi yaratmalıdır. Bu kapsamda organizasyonlarda yenilikçilik algısının ortaya çıkması için liderler, yenilikçilik faaliyetlerini teşvik etmeli ve bunun için uygun çevre ya da iklim sağlamalıdır (Wood vd., 2008:129). Değişimin sürekli olduğu bu pazarda yenilikçilik faaliyetleri organizasyonların vazgeçilmezi olmakla birlikte 
organizasyonlar başarı için memnun edici işgücü, tutku ve motiveyi devam ettirmek için ikna edici ve etkili iş ve organizasyon iklimi geliştirmelidir. Bunun gerçekleşmesi için bireylerin niyetleriyle ilgili motivasyon sağlayan yön vericiler açığa çıkartılarak iş çevresinde yaratıcılığı meydana getiren ortamın oluşması sağlanmalıdır (Bock, 2005:100).

$\mathrm{Bu}$ çalışma organizasyonların yenilikçilik yapıya sahip olması ve rekabet avantajı kazanabilmesi için organizasyon üyelerinin organizasyonu nasıl algıladığının önemli olduğunu göstermiştir. Bu çalışma insan kaynakları uygulamalarının bu kavramlar üzerindeki etkisini gösterdiğinden soyut kavramların nasıl girişimci yönelimi bağlamında yenilikçilik kavramına dönüştürülebileceğinin pratik yolunu da göstermektedir (Fiş ve Wasti, 2009:150).

Doktora tezimden çıkarılan bu araştırmanın girişimcilik yönelimi bağlamında yenilikçiliğe daha çok ihtiyacı olan Türkiye'de gerçekleştirilmiş olması, Türkiye'de ve gelişmekte olan diğer ülkelerde faaliyet gösteren üreticilere, firma yöneticilerine başarı sağlaması ve hedeflerini gerçekleştirmesi için pratik sonuçlar vereceği değerlendirilmektedir. Buradan çıkan sonuçları referans alarak bu çalışmanın daha ileri boyutlara ve farklı değişkenlerle ilişkisinin araştırılması bakımından gelecekteki akademik çalışmalara ilham kaynağı sağlayacağı ve okuyuculara uygun bir deneysel delil sağlayan bir çalışma olacağı umulmaktadır.

\section{KAYNAKÇA}

Altuntaş G. ve Dönmez D. (2010), "Girişimcilik Yönelimi ve Örgütsel Performans İlişkisi: Çanakkale Bölgesinde Faaliyet Gösteren Otel İşletmelerinde Bir Araştırma", İstanbul Üniversitesi İşletme Fakültesi Dergisi, C:39, No:1, ss. 50-74.

Autio, E. and Yli-Renko, H. (1998), "New, Technology - Based Arms as Agents of Technological Rejuvenation", Entrepreneurship \& Regional Development, 10: ss. 71-92.

Behram N.K. ve Özdemirci A. (2014), "The Empirical Link between Environmental Conditions, Organizational Culture, Corporate Entrepreneurship and Performance: The Mediating Role of Corporate Entrepreneurship", International Journal of Business and Social Science, C: 5 No: 2, ss. 264-276.

Bock G.W., Lee J.N., Zmud R.W. ve Kim Y.G. (2005), ” Behavioral Intention Formation In Knowledge Sharıng: Examınıng The Roles Of Extrinsic Motıvators, Social-Psychological Forces, and Organızational Clımate", MIS Quarterly, C: 29, No: 1, ss. 87-11.

Burton R.M., Lauridsen J. ve Obel B. (2004), "The Impact of Organizational Climate and Strategic Fit on Firm Performance”, Human Resource Management, C: 43, No: 1, ss. 67-82.

Chen C. J. ve Huang J.W. (2007), "How organizational climate and structure affect knowledge Management The social interaction perspective", International Journal of Information Management, 27, ss. 104118

Coda R., Silva D. ve Custodio I. (2015), "Multidimensional Configurations Of The Organizational Climate Construct", The International Journal of Human Resource Management, C: 26, No: 14, ss. 1827-1847. 
Covin J.G. ve Slevin D.P. (1989), "Strategic Management Of Small Firms in Hostıle and Benıng Environments" Strategic Management Journal, C: 10, ss. 75-87.

Covin, J.G. ve Slevin, D.P. (1991), "A conceptual model of entrepreneurship as Firm behavior", Entrepreneurship Theory and Practice, C:16, ss. 7-25.

Çekmecelioğlu H.G. (2006), "Örgüt İklimi, Duygusal Bağlllık Ve Yaratıcılık Arasındaki İlişkilerin Değerlendirilmesi: Bir Araştırma”, İktisadi ve İdari Bilimler Dergisi, C: 20, No: 2. ss. 295-310.

Fiş A.F. ve Wasti S.A. (2009), "Örgüt Kültürü ve Girişimcilik Yönelimi İlişkisi", ODTÜ Gelişme Dergisi, C: 35 , No: Özel Say1, ss. 127-164.

Guth W.D. ve Ginsberg A. (1990), "Guest Editors' Introduction: Corporate Entrepreneurship", Strategic Management Journal, C: 11, ss. 5-15.

Gürbüz S. ve Şahin F. (2015). Sosyal Bilimlerde Araştırma Yöntemleri Felsefe-Yöntem-Analiz, Seçkin Yayınları, Yayın No: 134, Ankara.

Halis M. ve Uğurlu Ö.Y. (2008), "Güncel Çalışmalar Işı̆̆ında Örgüt İklimi”, İş Güç Endüstri Ilişskileri ve Insan Kaynaklarl Dergisi, C: 10, No::2, ss.101-122.

Hayton J. ve Donna K. (2006), "Competency-Based Framework For Promotıng Corporate Entrepreneurshıp”, Human Resource Management, C: 45, No: 3, ss. 407-427.

Hayton, J.C. (2005), "Promoting Corporate Entrepreneurship Through Human Resource Management Practices: A Review of Empirical Research", Human Resource Management Review, C: 15, No: 1, ss. $21-41$.

Hitt, M. A., Nixon, R. D., Hoskisson, R. E. ve Kochlar, R. (1999), "Corporate Entrepreneurship and Crossfunctional Fertilization: Activation Process and Disintegration of a New Product Design Team", Entrepreneurship Theory and Practice, C:23, ss. 145-167.

Ireland R.D., Covin J.G. ve Kuratko D.F. (2009), "Conceptualizing Corporate Entrepreneurship Strategy", Entrepreneurship Theory And Practice, ss. 19-46

Knight, G.A. (1997), "Cross-Cultural Reliability and Validity of a Scale to Measure a Firm Entrepreneurial Orientation", Journal of Business Venturing, C:12, No: 3, ss. 213-225.

Lumpkin, G.T. ve Dess, G.G. (1996), "Clarifying the Entrepreneurial Orientation Construct and Linking it to Performance", Academy of Management Review, C: 21, No: 1, ss. 135-172.

Lumpkın, G.T. ve Dess, G.G. (2001), "Linking Two Dimensions of Entrepreneurial Orientation to Firm Performance: The Moderating Role of Environment and Industry Life Cycle", Journal of Business Venturing, 16, ss. 429-451.

Lumpkın G.T. ve Dess G.G. (2005), "The Role of Entrepreneurial Orientation in Stimulating Effective Corporate Entrepreneurship", Academy of Management Executive, C: 19, No: 1, ss. 147-156.

Ma'atoofi A.R. ve Tajeddini K. (2010),’The Effect of Entrepreneurship Orientation on Learning Orientation and Innovation: A Study of Small-Sized Business Firms in Iran", International Journal of Trade, Economics and Finance, C: 1, No:.3, ss. 254-260. 
Masomi E., Eghdami A., Asl M.D., Ashore S. ve Ghanimat P. (2013), "The Relationship Between Organizational Climate Dimensions and Corporate Entrepreneurship (Case Study: Meshkinshahr Payam Noor University, Iran)" Research Journal of Recent Sciences, C: 2, No: 1), ss. 107-113.

McGuinness, T., Morgan, R.E. (2005),"The Effect Of Market and Learning Orientation On Strategy Dynamics The Contributing Effect of Dynamics", European Journal of Marketing; C: 39, No: 11/12, ss. 1306-1392.

Merrifield, D. B. (2000),"Changing nature of competitive advantage”, Research Technology Management, C: 43 No: 1 , ss. $41-45$.

Miller, D. (1983),'The Correlates Of Entrepreneurship in Three Types Of Firms", Management Science, C: 29, No: 7, ss. 770-791.

Morris M.H., Webb J.W. ve RFranklin R.J. (2011)," Understanding the Manifestation of Entrepreneurial Orientation in the Nonprofit Context", Entrepreneurship Theory And Practice, ss. 947-971.

Neal A., West M.A. ve Patterson M.G. (2005), "Do Organizational Climate and Competitive Strategy Moderate the Relationship Between Human Resource Management and Productivity?", Journal of Management, C: 31, No: 4, ss. 492-512.

Rangriz H. (2012),"'Organizational Climate and Ambiguity Tolerance with Organizational Entrepreneurship: Empirical Study", Journal of Asia Entrepreneurship and Sustainability, C:8, No: 2 ss. 345-359.

Schneider, B., Brief, A. ve Guzzo, R. (1996)," Creating a Climate ve Culture for Sustainable Organizational Change" Organizational Dynamics, 24, ss. 6-20

Sekaran, U. (1992). Research Methods For Business, John Wiley ve Sons, Inc., Canada.

Sepehri S. ve Khayati E. (2013),"The Relationship Between Organızational Culture and Corporate Entrepreneurship in Food And Beverage Industries" Asian Journal Of Management Sciences And Education, C: 2, No: 3 ss. 144-151.

Sharma P, Chrisman J.J. (1999), "Toward a Reconciliation of the Definitional Issues in the Field of Corporate Entrepreneurship" Entrepreneurship Theory And Practice, ss. 11-27.

Tajeddini K. (2010), "Effect of customer orientation and entrepreneurial orientation on innovativeness: Evidence from the hotel industry in Switzerland", Tourism Management C:35, No:4, ss. 221-231.

Wannapa L. (2014),'Organization Climates and Individual Innovation" Advances in Management ve Applied Economics, C: 4, No:1, ss. 123-135.

Wood, C.C., Holt D.T., Reed T.S. ve Hudgens B.J. (2008), "Perceptions of Corporate Entrepreneurship in Air Force Organizations: Antecedents and Outcomes", Journal of Small Business and Entrepreneurship, C: 21, No: 1, ss. 117-132.

Yahyagil M.Y. (2006),"The fit between the concepts of Organizational culture and climate" Journal of Organizational Culture, Communications and Conflict, C: 10, No: 2, ss. 77-104

Yelkikalan N., Akatay A., Yıldırım H.M., Karadeniz Y., Köse C., Koncagül Ö., Özer E. (2010)” Dünya ve Türkiye Üniversitelerinde Girişimcilik Eğitimi: Karşılaştırmalı Bir Analiz" KMÜ Sosyal ve Ekonomik Araştırmalar Dergisi, C: 12, No: 19, ss. 51-59.

Yüceler A. (2009),’Örgütsel Bağlılık ve örgüt iklimi İlişkisi:Teorik ve Uygulamalı Bir Çalışma” Selçuk Üniversitesi Sosyal Bilimler Enstitüsü Dergisi 22/2009 
Zahra, S.A. ve Garvis, D.M. (2000),“International Corporate Entrepreneurship and Firm Performance: The Moderating Effect of International Environmental Hostility", Journal of BusinessVenturing,. C: 15 No: 5-6, ss. 469-492. 